\title{
Looking Back to the Future of Mitochondrial Research
}

\author{
Paolo Bernardi* \\ Department of Biomedical Sciences, University of Padova, Padova, Italy \\ Keywords: mitochondria, ATP synthase, channels, pathophysiology, hypoxia
}

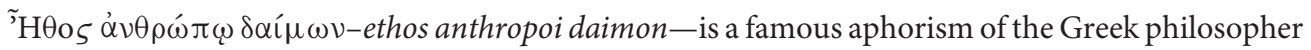
Heraclitus (544-483 BC). While its deeper meaning is probably more complex, the conventional translation is "a human being's character is his/her fate." When I was asked by George Billman to contribute my thoughts on the future of mitochondrial research it occurred to me that perhaps I could try to foretell the fate of mitochondrial research from its character, i.e., from the key themes from which the discipline developed. I will limit this brief comment to a few topics that also reflect my own interests, and that should not be considered even an attempt to be exhaustive. In the twentieth century the key issue in Bioenergetics (hence in mitochondrial research) has been the mechanism of energy conservation. The turning point was the proposal and then the demonstration of Peter Mitchell's chemiosmotic hypothesis, i.e., that in mitochondria the basic events are the coupling of aerobic electron transfer to $\mathrm{H}^{+}$pumping, the formation of the $\mathrm{H}^{+}$ electrochemical gradient and its harnessing by the ATP synthase (Mitchell, 1966), reprinted in Mitchell (2011). It is remarkable that the most recent advances in structural biology and superresolution microscopy, which are removing hurdles and moving the boundaries of Science beyond imagination, have confirmed the basic tenets of chemiosmotic principles in amazing detail.

\section{ATP SYNTHASE}

One example of how structural biology complemented physiology is the solution to the question of the $\mathrm{H}^{+}$/ATP stoichiometry, which had been the matter of considerable discussion (Brand and Lehninger, 1977; Sholtz et al., 1983). The demonstration that different organisms possess $\mathrm{c}$ rings (the rotating barrel powered by $\mathrm{H}^{+}$flux) with a number of subunits varying between a minimum of 8 and a maximum of 17, and the fact that one full rotation cycle generates 3 ATP molecules (Boyer, 1997) has both defined the precise stoichiometry for each type of $\mathrm{c}$ ring (between 2.67 and $5.67 \mathrm{H}^{+}$/ATP) and explained the apparent variability in the stoichiometry itself, see Nirody et al. (2020) for a review. While the basic structure and catalytic mechanism of ATP synthases is highly conserved across species, what is most puzzling is the existence of profound differences in the non-catalytic parts of the enzyme, which evolved to include a numer of subunits that were indeed defined "supernumerary" (Vaillier et al., 1999) because they are not essential for the catalytic activity. These subunits are involved in the process of dimerization and of membrane bending that contributes to generate the inner membrane cristae, which are then stabilized by the lateral association of dimers (Paumard et al., 2002; Dudkina et al., 2006; Jiko et al., 2015; Kühlbrandt, 2019; Spikes et al., 2021). And yet, clear species-specific differences exist in primary structure of these subunits, suggesting that they may serve additional function(s) that have not been fully discovered yet (Kühlbrandt, 2019). I think that research on the physiological function(s) of "supernumerary" subunits of ATP synthases (which may include the controversial formation of the high-conductance permeability transition pore) (Giorgio et al., 2013; Alavian et al., 2014; He et al., 2017a,b; Carroll et al., 2019; Mnatsakanyan et al., 2019; Urbani et al., 2019; Pinke et al., 2020) will be a very fruitful field of investigation in the years to come. 


\section{A SUPERCOMPLEX MATTER}

High-resolution definition of individual mitochondrial respiratory complexes, which begun over 20 years ago, has also yielded key information on the mechanisms of proton translocation coupled to electron transfer (Tsukihara et al., 1996; Xia et al., 1997; Michel et al., 1998; Baradaran et al., 2013; Zickermann et al., 2015; Kampjut and Sazanov, 2020). How electrons are transferred between respiratory complexes and whether this requires stable interactions is a question of great relevance, that to the best of my knowledge was clearly posed and addressed with inhibitor titration studies by Stoner (1984). The existence of respiratory supercomplexes made by associations of complexes I, III, and IV with defined stoichiometries in the native membrane is now established, and the role of supercomplexes in pathophysiology is increasingly appreciated (Schägger and Pfeiffer, 2000, 2001; Bianchi et al., 2004; Acín-Pérez et al., 2008; Dudkina et al., 2011; Lapuente-Brun et al., 2013; Letts et al., 2016; Milenkovic et al., 2017; Rathore et al., 2019; Berndtsson et al., 2020; Protasoni et al., 2020). An important question is the role of the supercomplex assembly factor SCAF1, which has been shown to promote supercomplex formation between CIII and IV $\left(\mathrm{III}_{2} \mathrm{IV}\right)$ and contribute to "branching" of the respiratory chain (Calvo et al., 2020). This topic is generating a very lively discussion that is likely to continue in the future (Mourier et al., 2014; Enríquez, 2016; Milenkovic et al., 2017; Lobo-Jarne et al., 2018; García-Poyatos et al., 2020; Protasoni et al., 2020; Fernández-Vizarra et al., 2021).

\section{DE(LOCALIZED) GRADIENTS?}

Another interesting question is whether $\mathrm{H}^{+}$pumping (together with the low permeability of the inner membrane) can generate a delocalized electric field rapidly spreading to the whole network (Amchenkova et al., 1988), or rather mitochondria should be seen as a mosaic of localized coupling units where the $\mathrm{H}^{+}$ pumping complexes and ATP synthases are closely spaced to make individual functional units without the need for lateral diffusion of charges (Yaguzhinsky et al., 2006), two hypotheses that may actually not be mutually exclusive (Westerhoff et al., 1986). Recent work using high resolution microscopy has demonstrated that both have merit and that, to some extent, the issue may be a matter of definition (i.e., what is meant by "short" and "long" range) and possibly of anatomy. Long range diffusion may predominate in tissues were mitochondria are mostly in the form of tubular, continuous structures (like in muscle) (Glancy et al., 2015) while local coupling (with formation of individual disc-shaped crista structures) may prevail where (or when) mitochondria are in the form of individual organelles (Wolf et al., 2019). This area of research has also made great progress on the fusion-fission events that regulate mitochondrial morphology and function (Giacomello et al., 2020). I think that superresolution microscopy together with the genetic manipulation of determinants of mitochondrial morphology will allow further definition of subcellular electrical events that bear both on mitochondrial function and on the shaping of localized ion gradients.

\section{MITOCHONDRIAL DYNAMICS}

Mitochondrial dynamics is a topic of enormous interest and of great additional potential in spite of the major progress made in recent years. The pioneering work of Jürgen Bereiter-Hahn provided a detailed description of mitochondrial motion and of fusion-fission events in vivo (Bereiter-Hahn, 1990; BereiterHahn and Voth, 1994). The molecular basis for mitochondrial dynamics is being unraveled at a steady pace, and is revealing the delicate balance between proteins that favor mitochondrial fusion and those that promote mitochondrial fission, their relationships with the cell cycle and with mitochondrial responses to pathophysiological perturbations (which depend on the cell type as much as on the stimulus), their role in cell survival and death, and their relationship to proteins that determine the maintenance of mitochondrial ultrastructure and its close interactions with the endoplasmic reticulum (Osteryoung and Nunnari, 2003; Mishra and Chan, 2016; Eisner et al., 2018; Giacomello et al., 2020).

\section{CATION CHANNELS}

When thinking of mitochondria and subcellular, localized ion gradients one obviously thinks of $\mathrm{Ca}^{2+}$ (Rizzuto et al., 1993) and this takes us to one of the paradoxes that accompanied the progressive acceptance of the chemiosmotic hypothesis. The existence of a proton electrochemical gradient as the energetic intermediate between respiration and ATP synthesis poses some constraints on membrane permeability to cations. Indeed, it was noted that equilibrium distribution of $\mathrm{K}^{+}$and $\mathrm{Ca}^{2+}$ across a membrane maintaining an electrical potential difference of $180 \mathrm{mV}$ (negative inside) would have meant matrix

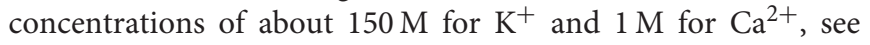
Bernardi (1999) for a detailed review. Mitchell was aware of this problem and conceived two complementary postulates to solve it. The first (3rd postulate of chemiosmosis) is that the inner membrane possesses electroneutral $\mathrm{H}^{+}$-cation exchangers allowing extrusion of cations entering the matrix down their electrochemical gradient. Operation of the exchangers (Mitchell and Moyle, 1969; Garlid, 1978, 1979) prevents the otherwise inevitable accumulation of cations that would lead to swelling and osmotic lysis of the organelle. The quest for the $\mathrm{K}^{+}-\mathrm{H}^{+}$ exchanger is still under way, although the LETM1 protein is clearly involved in mitochondrial cation homeostasis through modulation of the $\mathrm{K}^{+}-\mathrm{H}^{+}$exchange process (Nowikovsky et al., 2004, 2007) and possibly also of electroneutral $\mathrm{Ca}^{2+}$. $\mathrm{H}^{+}$exchange (Tsai et al., 2014), an issue that is still the matter of discussion (De Marchi et al., 2014; Nowikovsky and Bernardi, 2014), see Austin and Nowikovsky (2019) for a recent review. The second (4th postulate of chemiosmosis) is that the inner membrane has a low permeability to protons and to anions and cations generally (Mitchell, 1966, 2011). The latter point was almost universally (and as it turns out, erroneously) taken to mean that mitochondria could not possess channels for cations, a point that pervaded the literature well until the turn of last century (Garlid et al., 1989). This state of affairs considerably delayed the discovery of the mitochondrial $\mathrm{Ca}^{2+}$ uniporter (MCU) and its regulatory subunits (Perocchi 
et al., 2010; Baughman et al., 2011; De Stefani et al., 2011; Mallilankaraman et al., 2012; Sancak et al., 2013; Kamer and Mootha, 2014; Mammucari et al., 2016) and the assessment of their role in disease (Logan et al., 2014; Debattisti et al., 2019); and of mitochondrial $\mathrm{K}^{+}$channels (Inoue et al., 1991; Szewczyk et al., 2006; Szabó and Zoratti, 2014; Paggio et al., 2019). The great wave coming from these areas of research is unlikely to subside, and will translate in more breakthroughs on how mitochondrial participate and contribute to the shaping of intracellular ion gradients.

\section{INNER MEMBRANE PERMEABILITY AND PATHOPHYSIOLOGY}

As the chemiosmotic hypothesis became consolidated, a set of early observations on the $\mathrm{Ca}^{2+}$-dependent permeability increase to ions and solutes through "permeability defects" with a pore radius of $14 \AA$ (Massari and Azzone, 1972) became widely interpreted as an in vitro artifact of little relevance to mitochondrial physiology, see Bernardi et al. (2006) for a specific review. Only a few Authors interpreted the increased permeability (defined permeability transition, PT, by Haworth and Hunter) as a potentially regulated event serving a role in pathophysiology (Haworth and Hunter, 1979; Hunter and Haworth, 1979a,b; Pfeiffer et al., 1979; Crompton et al., 1987), possibly as a regulated pathway for $\mathrm{Ca}^{2+}$ release (Bernardi and Petronilli, 1996), which is consistent with a number of observations (Carraro et al., 2020). While today there is a general agreement that the PT is mediated by opening of a channel, its molecular identity is the matter of discussion. The latest results suggest that the PT can be mediated by a $\mathrm{Ca}^{2+}$ dependent conformational change of both the adenine nucleotide translocator (ANT) and the ATP synthase, through mechanisms that still need to be defined, see Carraro et al. (2020) for a discussion. The PT has been shown to play a role in necrotic cell death in a set of studies (Duchen et al., 1993; Imberti et al., 1993; Pastorino et al., 1993) that were greatly helped by the demonstration that the PT is inhibited by cyclosporin A (Fournier et al., 1987; Crompton et al., 1988; Broekemeier et al., 1989) through the matrix protein cyclophilin D (Halestrap and Davidson, 1990; Nicolli et al., 1996). The PT was then shown to play a role in apoptosis as well (Marchetti et al., 1996). Together with the discovery that cytochrome $c$ release from the intermembrane space triggers the mitochondrial pathway of apoptosis through activation of procaspase 9 (Liu et al., 1996), these studies opened a new season in mitochondrial research that is lasting to this day for its major implications in the pathogenesis of both degenerative diseases and cancer. Selective cytochome c release can be achieved by Bax/Bak-dependent permeabilization of the outer mitochondrial membrane following insertion of tBid generated by activation of caspase 8 (Wei et al., 2000) in a process that is substantially opposed by the antiapoptotic protein Bcl-2 (Susin et al., 1996; Yang et al., 1997). Release of cytochrome c can also be a consequence of PTP-dependent swelling (Petronilli et al., 1994) and/or cristae remodeling (Scorrano et al., 2002), and there is an intriguing promoting effect of Bax/Bak (Karch et al., 2013) and an inhibitory effect of Bcl-2 on onset of the PT (Susin et al., 1996). The latter is contrasted by Bcl-2 small molecule interactors (Milanesi et al., 2006) able to reactivate the mitochondrial death program (Oltersdorf et al., 2005) and these regulatory events extend to a variety of Bcl-2 family members (Singh et al., 2019). In a striking therapeutic development, the Bcl-2 ligand ABT-199 (venetoclax) has been introduced in the treatment of a variety of hematologic malignancies (Souers et al., 2013; de Ridder et al., 2021). It should also be mentioned that mitochondria play a key role in degenerative diseases, particularly muscular dystrophies and neurodegenerative conditions ranging from Parkinson's to Alzheimer diseases, amyotrophic lateral sclerosis, multiple sclerosis; and in organ ischemia-reperfusion injury. The mechanisms and targets, which include the PT, are so many that I will not even try to list them, but I would like to mention early work that anticipated these modern developments of mitochondrial pathophysiology (Hunter and Ford, 1955; Kasbekar and Sreenivasan, 1956; Hoch, 1962; Luft et al., 1962; Wollenberger et al., 1963; van Wijngaardeen et al., 1967; Sternlieb, 1968; Jennings et al., 1969; Fleckenstein et al., 1974; Wrogemann and Pena, 1976; Singer et al., 1987), see Bernardi et al. (2015) for relevant literature.

\section{ADENINE NUCLEOTIDE TRANSLOCATOR AND UNCOUPLING PROTEINS}

Another historical area of research where breakthroughs are being made is that of nucleotide transport via the ANT. It had long been proposed that the overall exchange of ADP for ATP was mediated by a single substrate-binding site alternately accessible from either side of the membrane (Klingenberg, 1979; Ruprecht et al., 2014). The most recent structures fully confirm this single-pore gating mechanism, whereby in energized mitochondria the nucleotide exchange reaction is mediated by unidirectional uptake of ADP and efflux of ATP "taking turns" on the carrier (Ruprecht et al., 2019). Many issues still await an answer, however. It has recently been shown that in the presence of arachidonic, palmitic or lauric acid the ANT can also transfer $\mathrm{H}^{+}$in mitochondria that do not express uncoupling protein 1 (UCP1) (Bertholet et al., 2019), the bona fide $\mathrm{H}^{+}$ channel that mediates non-shivering thermogenesis in brown fat (Nicholls, 1976; Rafael and Heldt, 1976). The existence of ANTmediated $\mathrm{H}^{+}$currents detected in patch-clamp experiments (Bertholet et al., 2019) supports the earlier suggestion that the ANT mediates a sizeable fraction of the " $\mathrm{H}^{+}$leaks" responsible for basal respiration (Andreyev et al., 1988; Brustovetsky and Klingenberg, 1994). ANT and UCP1 are closely related proteins and both require long-chain fatty acids for $\mathrm{H}^{+}$translocation and yet the molecular mechanisms appears to differ, as only in UCP1 the fatty acid anion participates in the actual mechanism of $\mathrm{H}^{+}$transport (Fedorenko et al., 2012) while it plays a cofactor role in ANT (Bertholet et al., 2019), see Bernardi (2019) for a summary. It will be interesting to test whether other members of the SLC25 superfamily of mitochondrial solute carriers (Palmieri and Monné, 2016) can mediate the occurrence of $\mathrm{H}^{+}$leaks. An additional open question about the ANT is how it can be 
transformed by $\mathrm{Ca}^{2+}$ in a high-conductance channel stimulated by cyclophilin $\mathrm{D}$ with an effect prevented by the cognate inhibitor of the latter cyclosporin A (Brustovetsky and Klingenberg, 1996; Brustovetsky et al., 2002), see Carraro et al. (2020) for a recent discussion.

\section{MITOCHONDRIAL DNA}

Mitochondria possess their own DNA and translation machinery. Diseases of mtDNA have first been described not so long ago (Wallace et al., 1988), and a new frontier is the manipulation of mtDNA, which holds great promise for a future correction of mtDNA diseases (Gammage et al., 2018) and possibly to treat cancer (Bonekamp et al., 2020). It is remarkable that only 13 out of the roughly 1,100 proteins found in mitochondria are encoded by mtDNA (Rath et al., 2020). During evolution mtDNA has retained only a core set of genes of the respiratory chain and F-ATP synthase, possibly to permit rapid adaptation to changing environments (Wallace, 2007). How mitochondrial and nuclear genomes integrate in mitochondrial biogenesis remains a fascinating topic (Becker et al., 2019) as is the somewhat specular issue of how cells exploit mitochondrial "diversity" by releasing into the circulation mitochondrial damage-associated molecular patterns (including mtDNA) to engage toll-like receptors and innate immune pathways (Zhang et al., 2010; Shintani et al., 2014; Rodríguez-Nuevo et al., 2018) and activate inflammation (Zhou et al., 2011; Oka et al., 2012; Zhong et al., 2018). This is strikingly similar to the effect of microbial pathogen-associated molecular patterns and provides an exciting link to STING, which regulates the type I interferon response (Sliter et al., 2018). The mechanism for mtDNA release is an interesting issue on its own, because it could be a regulated process mediated by the permeability transition pore (Yu et al., 2020) rather than the unspecific result of cell damage, an issue that will certainly attract more attention.

\section{AN UNEXPECTED TWIST ON HYPOXIA}

The discovery that mitochondria are involved in the HIFmediated response to hypoxia (Samanta and Semenza, 2018) through succinate-dependent stabilization of HIF- $1 \alpha$ (Selak et al., 2005) and modulation of expression of cytochrome oxidase subunits (Fukuda et al., 2007) was a turning point for our understanding of metabolic adaptation of tumors, first proposed as a causative event in cancer by Otto Warburg (Warburg et al., 1927; Warburg, 1956). A further mechanistic link was provided by the demonstration that TRAP1, a protein targeted to mitochondria in many tumors, inhibits succinate dehydrogenase and leads to succinate accumulation, stabilizing HIF- $1 \alpha$ under normoxic conditions and thus making tumor cells ready to resist the impending onset of hypoxia (Sciacovelli et al., 2013). The unexpected twist is that hypoxia has a beneficial effect in disorders of the respiratory chain through activation of an endogenous program that allows adaptation. Chronic hypoxia led to a marked improvement in survival and vital parameters in a mouse model of Leigh syndrome, an effect that could not be explained by activation of the HIF transcriptional program
(Jain et al., 2016). Rather, mice underwent an age-dependent decline in overall oxygen consumption with brain hyperoxia, which was normalized by hypoxic breathing, carbon monoxide or severe anemia with matching reversal of the neurological disease (Jain et al., 2019). These exciting new results suggest that unused oxygen rather than hypoxia itself may be the culprit, and open up new perspectives to normalize brain tissue hyperoxia (Jain et al., 2019). Genome-wide CRISPR screens at low oxygen tension have now identified genes with relative fitness defects in high or low oxygen, and most of these did not have an obvious connection to HIF (Jain et al., 2020). Remarkably, knockouts of mitochondrial pathways that are presumed to be essential, including complex I, grew relatively well at low oxygen (Jain et al., 2020). This approach is leading to the discovery of hundreds of genes linked to oxygen homeostasis, and there is more. Hypoxia has recently been shown to induce matrix acidification with release of $\mathrm{Ca}^{2+}$ from calcium phosphate precipitates, increased free $\left[\mathrm{Ca}^{2+}\right]$ and matrix influx of $\mathrm{Na}^{+}$on the $\mathrm{Na}^{+} / \mathrm{Ca}^{2+}$ exchanger (HernansanzAgustín et al., 2020). $\mathrm{Na}^{+}$interaction with phospholipids then reduced inner membrane fluidity, selectively decreasing mobility of free ubiquinone between complex II and III but not inside supercomplexes, thus leading to increased superoxide production at complex III, a novel control mechanism of redox signaling that may have profound consequences for cellular metabolism (Hernansanz-Agustín et al., 2020).

\section{INTRAORGANELLE BUFFERING}

Another topic that I find particularly fascinating is intramitochondrial communication between the two "arms" of oxidative phosphorylation, i.e., the respiratory chain and the ATP synthase. Respiratory complex III is assembled from a core containing cytochrome $\mathrm{b}$ (the only component encoded by mtDNA) and subunits Qcr7 and Qcr8, followed by the incorporation of all other subunits (Smith et al., 2012). As is the case with other respiratory complexes, specific proteins are required for the assembly of complex III including Bcs1 (Nobrega et al., 1992), an assembly factor that is the most frequent target of mutations in human complex III-related diseases. Extragenic compensatory mutations of yeast bcs 1 have been identified that preferentially target the ATP synthase complex, leading to selective decrease of its ATP hydrolytic activity with substantial preservation of ATP synthesis (Ostojic et al., 2013). Thus, the bioenergetics consequences of respiratory impairment appear to be limited by minimizing the hydrolysis of ATP. These results have recently been extended in a thorough study of the Mootha laboratory, who have found that the cellular defects derived from chemical inhibition of complex $\mathrm{V}$ with oligomycin are suppressed by loss of complex I activity induced by both genetic and pharmacological means (To et al., 2019). This is a striking example of "intra-organelle" buffering that was also seen for a variety of other mitochondrial inhibitors, suggesting that certain forms of mitochondrial dysfunction may be buffered with "second site" inhibition within the organelle (To et al., 2019). Consistent with the existence of a regulatory feedback between biogenesis of respiratory complexes and of 
the ATP synthase, ablation of specific subunits of ATP synthase (that largely prevented its assembly) caused a striking decrease of electron transfer chain complexes, with reduction of respiration to negligible rates (He et al., 2017a,b; Carroll et al., 2019).

\section{NOT ALL COULD BE PREDICTED}

The more I tried to cover new perspectives that are rooted in the history of mitochondrial research, the more I realized that my selective account was inevitably leaving out a number exciting developments. I will mention the relationships of autophagy with mitochondrial fission-fusion events (Twig et al., 2008; Lazarou et al., 2015; Dorn, 2016); the role of mitochondria in the antiviral response (Kozaki et al., 2017), in the growth of intracellular parasites (Pernas et al., 2018), in antigen presentation (Matheoud et al., 2016), in T cell function (Okoye et al., 2015; Weinberg et al., 2019) and dysfunction (Desdin-Mico et al., 2020), in metabolic reprogramming of macrophages (Mills et al., 2016; Acín-Pérez et al., 2020), in angiogenesis (Herkenne et al., 2020), in systemic stress response mediated by FGF21 (Forsstrom et al., 2019), in non-alcoholic steatohepatitis, where downregulation

\section{REFERENCES}

Acín-Pérez, R., Fernández-Silva, P., Peleato, M. L., Pérez-Martos, A., and Enriquez, J. A. (2008). Respiratory active mitochondrial supercomplexes. Mol. Cell 32, 529-539. doi: 10.1016/j.molcel.2008.10.021

Acín-Pérez, R., Iborra, S., Martí-Mateos, Y., Cook, E. C. L., Conde-Garrosa, R., Petcherski, A., et al. (2020). Fgr kinase is required for proinflammatory macrophage activation during diet-induced obesity. Nat. Metab. 2, 974-988. doi: $10.1038 / \mathrm{s} 42255-020-00273-8$

Alavian, K. N., Beutner, G., Lazrove, E., Sacchetti, S., Park, H. A., Licznerski, P., et al. (2014). An uncoupling channel within the $\mathrm{c}$-subunit ring of the $\mathrm{F}_{1} \mathrm{~F}_{\mathrm{O}}$ ATP synthase is the mitochondrial permeability transition pore. Proc. Natl. Acad. Sci. U.S.A. 111, 10580-10585. doi: 10.1073/pnas.1401591111

Amchenkova, A. A., Bakeeva, L. E., Chentsov, Y. S., Skulachev, V. P., and Zorov, D. B. (1988). Coupling membranes as energy-transmitting cables. I. Filamentous mitochondria in fibroblasts and mitochondrial clusters in cardiomyocytes. J. Cell Biol. 107, 481-495. doi: 10.1083/jcb.107.2.481

Andreyev, A. Y., Bondareva, T. O., Dedukhova, V. I., Mokhova, E. N., Skulachev, V. P., and Volkov, N. I. (1988). Carboxyatractylate inhibits the uncoupling effect of free fatty acids. FEBS Lett. 226, 265-269. doi: 10.1016/0014-5793(88)81436-4

Austin, S., and Nowikovsky, K. (2019). LETM1: Essential for Mitochondrial Biology and Cation Homeostasis? Trends Biochem. Sci. 44, 648-658. doi: 10.1016/j.tibs.2019.04.002

Baradaran, R., Berrisford, J. M., Minhas, G. S., and Sazanov, L. A. (2013). Crystal structure of the entire respiratory complex I. Nature 494, 443-448. doi: 10.1038/nature11871

Baughman, J. M., Perocchi, F., Girgis, H. S., Plovanich, M., Belcher-Timme, C. A., Sancak, Y., et al. (2011). Integrative genomics identifies MCU as an essential component of the mitochondrial calcium uniporter. Nature 476, 341-345. doi: $10.1038 /$ nature 10234

Becker, T., Song, J., and Pfanner, N. (2019). Versatility of preprotein transfer from the cytosol to mitochondria. Trends Cell. Biol. 29, 534-548. doi: $10.1016 /$ j.tcb.2019.03.007

Bereiter-Hahn, J. (1990). Behavior of mitochondria in the living cell. Int. Rev. Cytol. 122, 1-63. doi: 10.1016/S0074-7696(08)61205-X

Bereiter-Hahn, J., and Voth, M. (1994). Dynamics of mitochondria in living cells: shape changes, dislocations, fusion, and fission of mitochondria. Microsc. Res. Tech. 27, 198-219. doi: 10.1002/jemt.1070270303 of mitochondrial circular RNA prevents inhibition of the permeability transition pore by the SCAR protein (Zhao et al., 2020); recent advances on the mechanism of germline selection of human mtDNA (Wei et al., 2019); and the most unexpected finding that the protein product of the ARHGAP11B gene, which plays an essential role in development of the human neocortex (Heide et al., 2020), localizes to mitochondria to inhibit the permeability transition pore (Namba et al., 2020). It is reassuring, indeed, that not all could be predicted.

\section{AUTHOR CONTRIBUTIONS}

The author confirms being the sole contributor of this work and has approved it for publication.

\section{FUNDING}

Research in my laboratory was supported by Associazione Italiana Ricerca sul Cancro (IG17067), Fondation Leducq (16CVD04), the Italian Ministry for University and Research (2017LHFW42) and Telethon (GGP17092).

Bernardi, P. (1999). Mitochondrial transport of cations: channels, exchangers, and permeability transition. Physiol Rev. 79, 1127-1155. doi: 10.1152/physrev.1999.79.4.1127

Bernardi, P. (2019). Mitochondrial $\mathrm{H}^{+}$permeability through the ADP/ATP carrier. Nat. Metab. 1, 752-753. doi: 10.1038/s42255-019-0079-y

Bernardi, P., Krauskopf, A., Basso, E., Petronilli, V., Blachly-Dyson, E., Di Lisa, F., et al. (2006). The mitochondrial permeability transition from in vitro artifact to disease target. FEBS J. 273, 2077-2099. doi: 10.1111/j.1742-4658.2006.05213.x

Bernardi, P., and Petronilli, V. (1996). The permeability transition pore as a mitochondrial calcium release channel: a critical appraisal. J. Bioenerg. Biomembr. 28, 131-138. doi: 10.1007/BF02110643

Bernardi, P., Rasola, A., Forte, M., and Lippe, G. (2015). The mitochondrial permeability transition pore: channel formation by F-ATP synthase, integration in signal transduction, and role in pathophysiology. Physiol. Rev. 95, 1111-1155. doi: 10.1152/physrev.00001.2015

Berndtsson, J., Aufschnaiter, A., Rathore, S., Marin-Buera, L., Dawitz, H., Diessl, J., et al. (2020). Respiratory supercomplexes enhance electron transport by decreasing cytochrome c diffusion distance. EMBO Rep. 21, e51015. doi: 10.15252/embr.202051015

Bertholet, A. M., Chouchani, E. T., Kazak, L., Angelin, A., Fedorenko, A., Long, J. Z., et al. (2019). $\mathrm{H}^{+}$transport is an integral function of the mitochondrial ADP/ATP carrier. Nature 571, 515-520. doi: 10.1038/s41586-019-1400-3

Bianchi, C., Genova, M. L., Parenti Castelli, G., and Lenaz, G. (2004). The mitochondrial respiratory chain is partially organized in a supercomplex assembly: kinetic evidence using flux control analysis. J. Biol. Chem. 279, 36562-36569. doi: 10.1074/jbc.M405135200

Bonekamp, N. A., Peter, B., Hillen, H. S., Felser, A., Bergbrede, T., Choidas, A., et al. (2020). Small-molecule inhibitors of human mitochondrial DNA transcription. Nature 588, 712-716. doi: 10.1038/s41586-020-03048-z

Boyer, P. D. (1997). The ATP synthase-a splendid molecular machine. Annu. Rev. Biochem. 66, 717-749. doi: 10.1146/annurev.biochem.66.1.717

Brand, M. D., and Lehninger, A. L. (1977). $\mathrm{H}^{+} /$ATP ratio during ATP hydrolysis by mitochondria: modification of the chemiosmotic theory. Proc. Natl. Acad. Sci. U.S.A. 74, 1955-1959. doi: 10.1073/pnas.74.5.1955

Broekemeier, K. M., Dempsey, M. E., and Pfeiffer, D. R. (1989). Cyclosporin A is a potent inhibitor of the inner membrane permeability transition in liver mitochondria. J. Biol. Chem. 264, 7826-7830. doi: 10.1016/S0021-9258(18)83116-7 
Brustovetsky, N., and Klingenberg, M. (1994). The reconstituted ADP/ATP carrier can mediate $\mathrm{H}^{+}$transport by free fatty acids, which is further stimulated by mersalyl. J. Biol. Chem. 269, 27329-27336. doi: 10.1016/S0021-9258(18)46989-X

Brustovetsky, N., and Klingenberg, M. (1996). Mitochondrial ADP/ATP carrier can be reversibly converted into a large channel by $\mathrm{Ca}^{2+}$. Biochemistry 35 , 8483-8488. doi: 10.1021/bi960833v

Brustovetsky, N., Tropschug, M., Heimpel, S., Heidkamper, D., and Klingenberg, M. (2002). A large $\mathrm{Ca}^{2+}$-dependent channel formed by recombinant ADP/ATP carrier from Neurospora crassa resembles the mitochondrial permeability transition pore. Biochemistry 41, 11804-11811. doi: 10.1021/bi0200110

Calvo, E., Cogliati, S., Hernansanz-Agustín, P., Loureiro-Lopez, M., Guaras, A., Casuso, R. A., et al. (2020). Functional role of respiratory supercomplexes in mice: SCAF1 relevance and segmentation of the Qpool. Sci. Adv. 6:eaba7509. doi: 10.1126/sciadv.aba7509

Carraro, M., Carrer, A., Urbani, A., and Bernardi, P. (2020). Molecular nature and regulation of the mitochondrial permeability transition pore(s), drug target(s) in cardioprotection. J. Mol. Cell. Cardiol. 144, 76-86. doi: 10.1016/j.yjmcc.2020.05.014

Carroll, J., He, J., Ding, S., Fearnley, I. M., and Walker, J. E. (2019). Persistence of the permeability transition pore in human mitochondria devoid of an assembled ATP synthase. Proc. Natl Acad. Sci. U.S.A. 116, 12816-12821. doi: 10.1073/pnas.1904005116

Crompton, M., Costi, A., and Hayat, L. (1987). Evidence for the presence of a reversible $\mathrm{Ca}^{2+}$-dependent pore activated by oxidative stress in heart mitochondria. Biochem. J. 245, 915-918. doi: 10.1042/bj2450915

Crompton, M., Ellinger, H., and Costi, A. (1988). Inhibition by cyclosporin A of a $\mathrm{Ca}^{2+}$-dependent pore in heart mitochondria activated by inorganic phosphate and oxidative stress. Biochem. J. 255, 357-360.

De Marchi, U., Santo-Domingo, J., Castelbou, C., Sekler, I., Wiederkehr, A., and Demaurex, N. (2014). NCLX protein, but not LETM1, mediates mitochondrial $\mathrm{Ca}^{2+}$ extrusion, thereby limiting $\mathrm{Ca}^{2+}$-induced $\mathrm{NAD}(\mathrm{P}) \mathrm{H}$ production and modulating matrix redox state. J. Biol. Chem. 289, 20377-20385. doi: 10.1074/jbc.M113.540898

de Ridder, I., Kerkhofs, M., Veettil, S. P., Dehaen, W., and Bultynck, G. (2021). Cancer cell death strategies by targeting Bcl-2's BH4 domain. Biochim. Biophys. Acta Mol. Cell Res. 1868:118983. doi: 10.1016/j.bbamcr.2021.118983

De Stefani, D., Raffaello, A., Teardo, E., Szabó, I., and Rizzuto, R. (2011). A forty-kilodalton protein of the inner membrane is the mitochondrial calcium uniporter. Nature 476, 336-118340. doi: 10.1038/nature10230

Debattisti, V., Horn, A., Singh, R., Seifert, E. L., Hogarth, M. W., Mazala, D. A., et al. (2019). Dysregulation of mitochondrial $\mathrm{Ca}^{2+}$ uptake and sarcolemma repair underlie muscle weakness and wasting in patients and mice lacking MICU1. Cell Rep. 29, 1274-1286. doi: 10.1016/j.celrep.2019.09.063

Desdin-Mico, G., Soto-Heredero, G., Aranda, J. F., Oller, J., Carrasco, E., Gabande-Rodriguez, E., et al. (2020). T cells with dysfunctional mitochondria induce multimorbidity and premature senescence. Science 368, 1371-1376. doi: $10.1126 /$ science.aax 0860

Dorn, G. W. (2016). Central parkin: the evolving role of parkin in the heart. Biochim. Biophys. Acta 1857, 1307-1312. doi: 10.1016/j.bbabio.2016.03.014

Duchen, M. R., McGuinness, O., Brown, L. A., and Crompton, M. (1993). On the involvement of a cyclosporin A sensitive mitochondrial pore in myocardial reperfusion injury. Cardiovasc. Res. 27, 1790-1794. doi: 10.1093/cvr/27.10.1790

Dudkina, N. V., Kudryashev, M., Stahlberg, H., and Boekema, E. J. (2011). Interaction of complexes I, III, and IV within the bovine respirasome by single particle cryoelectron tomography. Proc. Natl. Acad. Sci. U.S.A. 108, 15196-15200. doi: 10.1073/pnas.1107819108

Dudkina, N. V., Sunderhaus, S., Braun, H. P., and Boekema, E. J. (2006). Characterization of dimeric ATP synthase and cristae membrane ultrastructure from Saccharomyces and Polytomella mitochondria. FEBS Lett. 580, 3427-3432. doi: 10.1016/j.febslet.2006.04.097

Eisner, V., Picard, M., and Hajnóczky, G. (2018). Mitochondrial dynamics in adaptive and maladaptive cellular stress responses. Nat. Cell Biol. 20, 755-765. doi: 10.1038/s41556-018-0133-0

Enríquez, J. A. (2016). Supramolecular organization of respiratory complexes. Annu. Rev. Physiol. 78, 533-561. doi: 10.1146/annurev-physiol-021115-105031

Fedorenko, A., Lishko, P. V., and Kirichok, Y. (2012). Mechanism of fatty-aciddependent UCP1 uncoupling in brown fat mitochondria. Cell 151, 400-413. doi: 10.1016/j.cell.2012.09.010
Fernández-Vizarra, E., López-Calcerrada, S., Formosa, L. E., Pérez-Pérez, R., Ding, S., Fearnley, I. M., et al. (2021). SILAC-based complexome profiling dissects the structural organization of the human respiratory supercomplexes in SCAFI ${ }^{\mathrm{KO}}$ cells. Biochim. Biophys. Acta 1862:148414. doi: 10.1016/j.bbabio.2021.148414

Fleckenstein, A., Janke, J., Doring, H. J., and Leder, O. (1974). Myocardial fiber necrosis due to intracellular Ca overload-a new principle in cardiac pathophysiology. Recent Adv. Stud. Cardiac. Struct. Metab. 4, 563-580.

Forsstrom, S., Jackson, C. B., Carroll, C. J., Kuronen, M., Pirinen, E., Pradhan, S., et al. (2019). Fibroblast growth factor 21 drives dynamics of local and systemic stress responses in mitochondrial myopathy with mtDNA deletions. Cell Metab. 30, 1040-1054. doi: 10.1016/j.cmet.2019.08.019

Fournier, N., Ducet, G., and Crevat, A. (1987). Action of cyclosporine on mitochondrial calcium fluxes. J. Bioenerg. Biomembr. 19, 297-303. doi: 10.1007/BF00762419

Fukuda, R., Zhang, H., Kim, J. W., Shimoda, L., Dang, C. V., and Semenza, G. L. (2007). HIF-1 regulates cytochrome oxidase subunits to optimize efficiency of respiration in hypoxic cells. Cell 129, 111-122. doi: 10.1016/j.cell.2007.01.047

Gammage, P. A., Moraes, C. T., and Minczuk, M. (2018). Mitochondrial genome engineering: the revolution may not be CRISPR-Ized. Trends Genet. 34, 101-110. doi: 10.1016/j.tig.2017.11.001

García-Poyatos, C., Cogliati, S., Calvo, E., Hernansanz-Agustín, P., Lagarrigue, S., Magni, R., et al. (2020). Scaf1 promotes respiratory supercomplexes and metabolic efficiency in zebrafish. EMBO Rep. 21:e50287. doi: $10.15252 / \mathrm{embr} .202050287$

Garlid, K. D. (1978). Unmasking the mitochondrial K/H exchanger: swellinginduced $\mathrm{K}^{+}$-loss. Biochem. Biophys. Res. Commun. 83, 1450-1455. doi: 10.1016/0006-291X(78)91383-9

Garlid, K. D. (1979). Unmasking the mitochondrial K/H exchanger: tetraethylammonium-induced $\mathrm{K}^{+}$-loss. Biochem. Biophys. Res. Commun. 87, 842-847. doi: 10.1016/0006-291X(79)92034-5

Garlid, K. D., Beavis, A. D., and Ratkje, S. K. (1989). On the nature of ion leaks in energy-transducing membranes. Biochim. Biophys. Acta 976, 109-120. doi: 10.1016/S0005-2728(89)80219-1

Giacomello, M., Pyakurel, A., Glytsou, C., and Scorrano, L. (2020). The cell biology of mitochondrial membrane dynamics. Nat. Rev. Mol. Cell Biol. 21, 204-224. doi: 10.1038/s41580-020-0210-7

Giorgio, V., von Stockum, S., Antoniel, M., Fabbro, A., Fogolari, F., Forte, M., et al. (2013). Dimers of mitochondrial ATP synthase form the permeability transition pore. Proc. Natl. Acad. Sci. U.S.A. 110, 5887-5892. doi: $10.1073 /$ pnas.1217823110

Glancy, B., Hartnell, L. M., Malide, D., Yu, Z. X., Combs, C. A., Connelly, P. S., et al. (2015). Mitochondrial reticulum for cellular energy distribution in muscle. Nature 523, 617-620. doi: 10.1038/nature14614

Halestrap, A. P., and Davidson, A. M. (1990). Inhibition of $\mathrm{Ca}^{2+}$-induced largeamplitude swelling of liver and heart mitochondria by cyclosporin is probably caused by the inhibitor binding to mitochondrial-matrix peptidyl-prolyl cistrans isomerase and preventing it interacting with the adenine nucleotide translocase. Biochem. J. 268, 153-160. doi: 10.1042/bj2680153

Haworth, R. A., and Hunter, D. R. (1979). The $\mathrm{Ca}^{2+}$-induced membrane transition in mitochondria. II. Nature of the $\mathrm{Ca}^{2+}$ trigger site. Arch. Biochem. Biophys. 195, 460-467. doi: 10.1016/0003-9861(79)90372-2

He, J., Carroll, J., Ding, S., Fearnley, I. M., and Walker, J. E. (2017a). Permeability transition in human mitochondria persists in the absence of peripheral stalk subunits of ATP synthase. Proc. Natl. Acad. Sci. U.S.A. 114, 9086-9091. doi: 10.1073/pnas.1711201114

He, J., Ford, H. C., Carroll, J., Ding, S., Fearnley, I. M., and Walker, J. E. (2017b). Persistence of the mitochondrial permeability transition in the absence of subunit c of human ATP synthase. Proc. Natl. Acad. Sci. U.S.A. 114, 3409-3414. doi: 10.1073/pnas. 1702357114

Heide, M., Haffner, C., Murayama, A., Kurotaki, Y., Shinohara, H., Okano, H., et al. (2020). Human-specific ARHGAP11B increases size and folding of primate neocortex in the fetal marmoset. Science 369, 546-550. doi: $10.1126 /$ science.abb2401

Herkenne, S., Ek, O., Zamberlan, M., Pellattiero, A., Chergova, M., Chivite, I., et al. (2020). Developmental and tumor angiogenesis requires the mitochondria-shaping protein Opa1. Cell Metab. 31, 987-1003. doi: 10.1016/j.cmet.2020.04.007

Hernansanz-Agustín, P., Choya-Foces, C., Carregal-Romero, S., Ramos, E., Oliva, T., Villa-Piña, T., et al. (2020). $\mathrm{Na}^{+}$controls hypoxic 
signalling by the mitochondrial respiratory chain. Nature 586, 287-291. doi: 10.1038/s41586-020-2551-y

Hoch, F. L. (1962). Thyrotoxicosis as a disease of mitochondria. N. Engl. J. Med. 266, 498-505. doi: 10.1056/NEJM196203082661007

Hunter, D. R., and Haworth, R. A. (1979a). The $\mathrm{Ca}^{2+}$-induced membrane transition in mitochondria. I. The protective mechanisms. Arch. Biochem. Biophys. 195, 453-459. doi: 10.1016/0003-9861(79)90371-0

Hunter, D. R., and Haworth, R. A. (1979b). The $\mathrm{Ca}^{2+}$-induced membrane transition in mitochondria. III. Transitional $\mathrm{Ca}^{2+}$ release. Arch. Biochem. Biophys. 195, 468-477. doi: 10.1016/0003-9861(79)90373-4

Hunter, Jr., F. E., and Ford, L. (1955). Inactivation of oxidative and phosphorylative systems in mitochondria by preincubation with phosphate and other ions. J. Biol. Chem. 216, 357-369. doi: 10.1016/S0021-9258(19)52312-2

Imberti, R., Nieminen, A. L., Herman, B., and Lemasters, J. J. (1993). Mitochondrial and glycolytic dysfunction in lethal injury to hepatocytes by tbutylhydroperoxide: protection by fructose, cyclosporin A and trifluoperazine. J. Pharmacol. Exp. Ther. 265, 392-400.

Inoue, I., Nagase, H., Kishi, K., and Higuti, T. (1991). ATP-sensitive $\mathrm{K}^{+}$ channel in the mitochondrial inner membrane. Nature 352, 244-247. doi: $10.1038 / 352244 \mathrm{a} 0$

Jain, I. H., Calvo, S. E., Markhard, A. L., Skinner, O. S., To, T. L., Ast, T., et al. (2020). Genetic screen for cell fitness in high or low oxygen highlights mitochondrial and lipid metabolism. Cell 181, 716-727. doi: 10.1016/j.cell.2020.03.029

Jain, I. H., Zazzeron, L., Goldberger, O., Marutani, E., Wojtkiewicz, G. R., Ast, T., et al. (2019). Leigh syndrome mouse model can be rescued by interventions that normalize brain hyperoxia, but not HIF activation. Cell Metab. 30, 824-832. doi: 10.1016/j.cmet.2019.07.006

Jain, I. H., Zazzeron, L., Goli, R., Alexa, K., Schatzman-Bone, S., Dhillon, H., et al. (2016). Hypoxia as a therapy for mitochondrial disease. Science 352, 54-61. doi: $10.1126 /$ science.aad 9642

Jennings, R. B., Herdson, P. B., and Sommers, H. M. (1969). Structural and functional abnormalities in mitochondria isolated from ischemic dog myocardium. Lab. Invest. 20, 548-557.

Jiko, C., Davies, K. M., Shinzawa-Itoh, K., Tani, K., Maeda, S., Mills, D. J., et al. (2015). Bovine F1Fo ATP synthase monomers bend the lipid bilayer in 2D membrane crystals. eLife Sci. 4:e06119. doi: 10.7554/eLife.06119.022

Kamer, K. J., and Mootha, V. K. (2014). MICU1 and MICU2 play nonredundant roles in the regulation of the mitochondrial calcium uniporter. EMBO Rep. 15, 299-307. doi: 10.1002/embr.201337946

Kampjut, D., and Sazanov, L. A. (2020). The coupling mechanism of mammalian respiratory complex I. Science 370:547. doi: 10.1126/science.abc4209

Karch, J., Kwong, J. Q., Burr, A. R., Sargent, M. A., Elrod, J. W., Peixoto, P. M., et al. (2013). Bax and bak function as the outer membrane component of the mitochondrial permeability pore in regulating necrotic cell death in mice. eLife Sci. 2:e00772. doi: 10.7554/eLife.00772.020

Kasbekar, D. K., and Sreenivasan, A. (1956). Lability of intramitochondrial components in experimental liver injury. Nature 178, 989-990. doi: $10.1038 / 178989 b 0$

Klingenberg, M. (1979). The ADP,ATP shuttle of the mitochondrion. Trends Biochem. Sci. 4, 249-252. doi: 10.1016/0968-0004(79)90215-9

Kozaki, T., Komano, J., Kanbayashi, D., Takahama, M., Misawa, T., Satoh, T., et al. (2017). Mitochondrial damage elicits a TCDD-inducible poly(ADPribose) polymerase-mediated antiviral response. Proc. Natl. Acad. Sci. U.S.A. 114, 2681-2686. doi: 10.1073/pnas.1621508114

Kühlbrandt, W. (2019). Structure and mechanisms of F-type ATP synthases. Annu. Rev. Biochem. 88, 515-549. doi: 10.1146/annurev-biochem-013118-1 10903

Lapuente-Brun, E., Moreno-Loshuertos, R., Acín-Pérez, R., Latorre-Pellicer, A., Colás, C., Balsa, E., et al. (2013). Supercomplex assembly determines electron flux in the mitochondrial electron transport chain. Science 340, 1567-1570. doi: 10.1126/science.1230381

Lazarou, M., Sliter, D. A., Kane, L. A., Sarraf, S. A., Wang, C., Burman, J. L., et al. (2015). The ubiquitin kinase PINK1 recruits autophagy receptors to induce mitophagy. Nature 524, 309-314. doi: 10.1038/nature14893

Letts, J. A., Fiedorczuk, K., and Sazanov, L. A. (2016). The architecture of respiratory supercomplexes. Nature 537, 644-648. doi: 10.1038/nature 19774
Liu, X., Kim, C. N., Yang, J., Jemmerson, R., and Wang, X. (1996). Induction of apoptotic program in cell-free extracts: requirement for dATP and cytochrome c. Cell 86, 147-157. doi: 10.1016/S0092-8674(00)80085-9

Lobo-Jarne, T., Nývltová, E., Pérez-Pérez, R., Timón-Gómez, A., Molinié, T., Choi, A., et al. (2018). Human COX7A2L Regulates complex III biogenesis and promotes supercomplex organization remodeling without affecting mitochondrial bioenergetics. Cell Rep. 25, 1786-1799. doi: 10.1016/j.celrep.2018.10.058

Logan, C. V., Szabadkai, G., Sharpe, J. A., Parry, D. A., Torelli, S., Childs, A. M., et al. (2014). Loss-of-function mutations in MICU1 cause a brain and muscle disorder linked to primary alterations in mitochondrial calcium signaling. Nat. Genet. 46, 188-193. doi: 10.1038/ng.2851

Luft, R., Ikkos, D., Palmieri, G., Ernster, L., and Afzelius, B. (1962). A case of severe hypermetabolism of nonthyroid origin with a defect in the maintenance of mitochondrial respiratory control: a correlated clinical, biochemical, and morphological study. J. Clin. Invest. 41, 1776-1804. doi: 10.1172/JCI104637

Mallilankaraman, K., Cardenas, C., Doonan, P. J., Chandramoorthy, H. C., Irrinki, K. M., Golenar, T., et al. (2012). MCUR1 is an essential component of mitochondrial $\mathrm{Ca}^{2+}$ uptake that regulates cellular metabolism. Nat. Cell Biol. 15:123. doi: $10.1038 /$ ncb2669

Mammucari, C., Raffaello, A., Vecellio Reane, D., and Rizzuto, R. (2016). Molecular structure and pathophysiological roles of the mitochondrial calcium uniporter. Biochim. Biophys. Acta 1863, 2457-2464. doi: 10.1016/j.bbamcr.2016.03.006

Marchetti, P., Castedo, M., Susin, S. A., Zamzami, N., Hirsch, T., Macho, A., et al. (1996). Mitochondrial permeability transition is a central coordinating event of apoptosis. J. Exp. Med. 184, 1155-1160. doi: 10.1084/jem.184.3.1155

Massari, S., and Azzone, G. F. (1972). The equivalent pore radius of intact and damaged mitochondria and the mechanism of active shrinkage. Biochim. Biophys. Acta 283, 23-29. doi: 10.1016/0005-2728(72)90094-1

Matheoud, D., Sugiura, A., Bellemare-Pelletier, A., Laplante, A., Rondeau, C., Chemali, M., et al. (2016). Parkinson's disease-related proteins PINK1 and parkin repress mitochondrial antigen presentation. Cell 166, 314-327. doi: 10.1016/j.cell.2016.05.039

Michel, H., Behr, J., Harrenga, A., and Kannt, A. (1998). Cytochrome c oxidase: structure and spectroscopy. Annu. Rev. Biophys. Biomol. Struct. 27, 329-356. doi: 10.1146/annurev.biophys.27.1.329

Milanesi, E., Costantini, P., Gambalunga, A., Colonna, R., Petronilli, V., Cabrelle, A., et al. (2006). The mitochondrial effects of small organic ligands of BCL-2: sensitization of BCL-2-overexpressing cells to apoptosis by a pyrimidine-2,4,6-trione derivative. J. Biol. Chem. 281, 10066-10072. doi: 10.1074/jbc.M513708200

Milenkovic, D., Blaza, J. N., Larsson, N. G., and Hirst, J. (2017). The enigma of the respiratory chain supercomplex. Cell Metab. 25, 765-776. doi: 10.1016/j.cmet.2017.03.009

Mills, E. L., Kelly, B., Logan, A., Costa, A. S. H., Varma, M., Bryant, C. E., et al. (2016). Succinate dehydrogenase supports metabolic repurposing of mitochondria to drive inflammatory macrophages. Cell 167, 457-470. doi: 10.1016/j.cell.2016.08.064

Mishra, P., and Chan, D. C. (2016). Metabolic regulation of mitochondrial dynamics. J. Cell Biol. 212, 379-387. doi: 10.1083/jcb.201511036

Mitchell, P. (1966). Chemiosmotic Coupling in Oxidative and Photosynthetic Phosphorylation. Bodmin: Glynn Research. doi: 10.1111/j.1469-185X.1966.tb01501.x

Mitchell, P. (2011). Chemiosmotic coupling in oxidative and photosynthetic phosphorylation. 1966. Biochim. Biophys. Acta 1807, 1507-1538. doi: 10.1016/j.bbabio.2011.09.018

Mitchell, P., and Moyle, J. (1969). Translocation of some anions cations and acids in rat liver mitochondria. Eur. J. Biochem. 9, 149-155. doi: 10.1111/j.1432-1033.1969.tb00588.x

Mnatsakanyan, N., Llaguno, M. C., Yang, Y., Yan, Y., Weber, J., Sigworth, F. J., et al. (2019). A mitochondrial megachannel resides in monomeric F1FO ATP synthase. Nat. Commun. 10:5823. doi: 10.1038/s41467-019-13766-2

Mourier, A., Matic, S., Ruzzenente, B., Larsson, N. G., and Milenkovic, D. (2014). The respiratory chain supercomplex organization is independent of COX7a2l isoforms. Cell Metab. 20, 1069-1075. doi: 10.1016/j.cmet.2014.11.005

Namba, T., Doczi, J., Pinson, A., Xing, L., Kalebic, N., Wilsch-Brauninger, M., et al. (2020). Human-specific ARHGAP11B acts in mitochondria to 
expand neocortical progenitors by glutaminolysis. Neuron 105, 867-881. doi: 10.1016/j.neuron.2019.11.027

Nicholls, D. G. (1976). Hamster brown-adipose-tissue mitochondria. Purine nucleotide control of the ion conductance of the inner membrane, the nature of the nucleotide binding site. Eur. J. Biochem. 62, 223-228. doi: 10.1111/j.1432-1033.1976.tb10151.x

Nicolli, A., Basso, E., Petronilli, V., Wenger, R. M., and Bernardi, P. (1996). Interactions of cyclophilin with the mitochondrial inner membrane and regulation of the permeability transition pore, a cyclosporin A-sensitive channel. J. Biol. Chem. 271, 2185-2192. doi: 10.1074/jbc.271.4.2185

Nirody, J. A., Budin, I., and Rangamani, P. (2020). ATP synthase: evolution, energetics, and membrane interactions. J. Gen. Physiol. 152:e201912475. doi: 10.1085/jgp.201912475

Nobrega, F. G., Nobrega, M. P., and Tzagoloff, A. (1992). BCS1, a novel gene required for the expression of functional Rieske ironsulfur protein in Saccharomyces cerevisiae. EMBO J. 11, 3821-3829. doi: 10.1002/j.1460-2075.1992.tb05474.x

Nowikovsky, K., and Bernardi, P. (2014). LETM1 in mitochondrial cation transport. Front. Physiol. 5:83. doi: 10.3389/fphys.2014.00083

Nowikovsky, K., Froschauer, E. M., Zsurka, G., Samaj, J., Reipert, S., Kolisek, M., et al. (2004). The LETM1/YOL027 gene family encodes a factor of the mitochondrial $\mathrm{K}^{+}$homeostasis with a potential role in the wolf-hirschhorn syndrome. J. Biol. Chem. 279, 30307-30315. doi: 10.1074/jbc.M403607200

Nowikovsky, K., Reipert, S., Devenish, R. J., and Schweyen, R. J. (2007). Mdm38 protein depletion causes loss of mitochondrial $\mathrm{K}^{+} / \mathrm{H}^{+}$exchange activity, osmotic swelling and mitophagy. Cell Death Differ. 14, 1647-1656. doi: $10.1038 /$ sj.cdd.4402167

Oka, T., Hikoso, S., Yamaguchi, O., Taneike, M., Takeda, T., Tamai, T., et al. (2012). Mitochondrial DNA that escapes from autophagy causes inflammation and heart failure. Nature 485, 251-255. doi: 10.1038/nature10992

Okoye, I., Wang, L., Pallmer, K., Richter, K., Ichimura, T., Haas, R., et al. (2015). T cell metabolism. The protein LEM promotes CD8 ${ }^{+} \mathrm{T}$ cell immunity through effects on mitochondrial respiration. Science 348, 995-1001. doi: 10.1126/science.aaa7516

Oltersdorf, T., Elmore, S. W., Shoemaker, A. R., Armstrong, R. C., Augeri, D. J., Belli, B. A., et al. (2005). An inhibitor of Bcl-2 family proteins induces regression of solid tumours. Nature 435, 677-681. doi: 10.1038/nature03579

Osteryoung, K. W., and Nunnari, J. (2003). The division of endosymbiotic organelles. Science 302, 1698-1704. doi: 10.1126/science.1082192

Ostojic, J., Panozzo, C., Lasserre, J. P., Nouet, C., Courtin, F., Blancard, C., et al. (2013). The energetic state of mitochondria modulates complex III biogenesis through the ATP-dependent activity of Bcs1. Cell Metab. 18, 567-577. doi: 10.1016/j.cmet.2013.08.017

Paggio, A., Checchetto, V., Campo, A., Menabò, R., Di Marco, G., Di Lisa, F., et al. (2019). Identification of an ATP-sensitive potassium channel in mitochondria. Nature 572, 609-613. doi: 10.1038/s41586-019-1498-3

Palmieri, F., and Monné, M. (2016). Discoveries, metabolic roles and diseases of mitochondrial carriers: a review. Biochim. Biophys. Acta 1863, 2362-2378. doi: 10.1016/j.bbamcr.2016.03.007

Pastorino, J. G., Snyder, J. W., Serroni, A., Hoek, J. B., and Farber, J. L. (1993). Cyclosporin and carnitine prevent the anoxic death of cultured hepatocytes by inhibiting the mitochondrial permeability transition. J. Biol. Chem. 268, 13791-13798. doi: 10.1016/S0021-9258(19)85172-4

Paumard, P., Vaillier, J., Coulary, B., Schaeffer, J., Soubannier, V., Mueller, D. M., et al. (2002). The ATP synthase is involved in generating mitochondrial cristae morphology. EMBO J. 21, 221-230. doi: 10.1093/emboj/21.3.221

Pernas, L., Bean, C., Boothroyd, J. C., and Scorrano, L. (2018). Mitochondria restrict growth of the intracellular parasite Toxoplasma gondii by limiting its uptake of fatty acids. Cell Metab. 27, 886-897. doi: 10.1016/j.cmet.2018.02.018

Perocchi, F., Gohil, V. M., Girgis, H. S., Bao, X. R., McCombs, J. E., Palmer, A. E., et al. (2010). MICU1 encodes a mitochondrial EF hand protein required for $\mathrm{Ca}^{2+}$ uptake. Nature 467, 291-296. doi: 10.1038/nature09358

Petronilli, V., Nicolli, A., Costantini, P., Colonna, R., and Bernardi, P. (1994). Regulation of the permeability transition pore, a voltage-dependent mitochondrial channel inhibited by cyclosporin A. Biochim. Biophys. Acta 1187, 255-259. doi: 10.1016/0005-2728(94)90122-8

Pfeiffer, D. R., Schmid, P. C., Beatrice, M. C., and Schmid, H. H. (1979). Intramitochondrial phospholipase activity and the effects of $\mathrm{Ca}^{2+}$ plus
N-ethylmaleimide on mitochondrial function. J. Biol. Chem. 254, 11485-11494. doi: 10.1016/S0021-9258(19)86511-0

Pinke, G., Zhou, L., and Sazanov, L. A. (2020). Cryo-EM structure of the entire mammalian F-type ATP synthase. Nat. Struct. Mol. Biol. 27, 1077-1085. doi: 10.1038/s41594-020-0503-8

Protasoni, M., Pérez-Pérez, R., Lobo-Jarne, T., Harbour, M. E., Ding, S., Peñas, A., et al. (2020). Respiratory supercomplexes act as a platform for complex IIImediated maturation of human mitochondrial complexes I and IV. EMBO J. 39, e102817. doi: 10.15252/embj.2019102817

Rafael, J., and Heldt, H. W. (1976). Binding of guanine nucleotides to the outer surface of the inner membrane of guinea pig brown fat mitochondria in correlation with the thermogenic activity of the tissue. FEBS Lett. 63, 304-308. doi: 10.1016/0014-5793(76)80117-2

Rath, S., Sharma, R., Gupta, R., Ast, T., Chan, C., Durham, T. J., et al. (2020). MitoCarta3.0: an updated mitochondrial proteome now with sub-organelle localization and pathway annotations. Nucleic Acids Res. 49, D1541-D1547. doi: 10.1093/nar/gkaa1011

Rathore, S., Berndtsson, J., Marin-Buera, L., Conrad, J., Carroni, M., Brzezinski, P., et al. (2019). Cryo-EM structure of the yeast respiratory supercomplex. Nat. Struct. Mol. Biol. 26, 50-57. doi: 10.1038/s41594-018-0169-7

Rizzuto, R., Brini, M., Murgia, M., and Pozzan, T. (1993). Microdomains with high $\mathrm{Ca}^{2+}$ close to IP3-sensitive channels that are sensed by neighboring mitochondria. Science 262, 744-747. doi: 10.1126/science.8235595

Rodríguez-Nuevo, A., Díaz-Ramos, A., Noguera, E., Díaz-Sáez, F., Duran, X., Muñoz, J. P., et al. (2018). Mitochondrial DNA and TLR9 drive muscle inflammation upon Opal deficiency. EMBO J. 37: e96553. doi: 10.15252/embj.201796553

Ruprecht, J. J., Hellawell, A. M., Harding, M., Crichton, P. G., McCoy, A. J., and Kunji, E. R. (2014). Structures of yeast mitochondrial ADP/ATP carriers support a domain-based alternating-access transport mechanism. Proc. Natl. Acad. Sci. U.S.A. 111, E426-E434. doi: 10.1073/pnas.1320692111

Ruprecht, J. J., King, M. S., Zogg, T., Aleksandrova, A. A., Pardon, E., Crichton, P. G., et al. (2019). The molecular mechanism of transport by the mitochondrial ADP/ATP carrier. Cell 176, 435-447. doi: 10.1016/j.cell.2018.11.025

Samanta, D., and Semenza, G. L. (2018). Metabolic adaptation of cancer and immune cells mediated by hypoxia-inducible factors. Biochim. Biophys. Acta Rev. Cancer 1870, 15-22. doi: 10.1016/j.bbcan.2018.07.002

Sancak, Y., Markhard, A. L., Kitami, T., Kovacs-Bogdan, E., Kamer, K. J., Udeshi, N. D., et al. (2013). EMRE is an essential component of the mitochondrial calcium uniporter complex. Science 342, 1379-1382. doi: $10.1126 /$ science. 1242993

Schägger, H., and Pfeiffer, K. (2000). Supercomplexes in the respiratory chains of yeast and mammalian mitochondria. EMBO J. 19, 1777-1783. doi: 10.1093/emboj/19.8.1777

Schägger, H., and Pfeiffer, K. (2001). The ratio of oxidative phosphorylation complexes $\mathrm{I}-\mathrm{V}$ in bovine heart mitochondria and the composition of respiratory chain supercomplexes. J. Biol. Chem. 276, 37861-37867. doi: 10.1074/jbc.M106474200

Sciacovelli, M., Guzzo, G., Morello, V., Frezza, C., Zheng, L., Nannini, N., et al. (2013). The mitochondrial chaperone TRAP1 promotes neoplastic growth by inhibiting succinate dehydrogenase. Cell Metab. 17, 988-999. doi: 10.1016/j.cmet.2013.04.019

Scorrano, L., Ashiya, M., Buttle, K., Weiler, S., Oakes, S. A., Mannella, C. A., et al. (2002). A distinct pathway remodels mitochondrial cristae and mobilizes cytochrome c during apoptosis. Dev. Cell 2, 55-67. doi: 10.1016/S1534-5807(01)00116-2

Selak, M. A., Armour, S. M., MacKenzie, E. D., Boulahbel, H., Watson, D. G., Mansfield, K. D., et al. (2005). Succinate links TCA cycle dysfunction to oncogenesis by inhibiting HIF- $\alpha$ prolyl hydroxylase. Cancer Cell 7, 77-85. doi: 10.1016/j.ccr.2004.11.022

Shintani, Y., Drexler, H. C., Kioka, H., Terracciano, C. M., Coppen, S. R., Imamura, H., et al. (2014). Toll-like receptor 9 protects non-immune cells from stress by modulating mitochondrial ATP synthesis through the inhibition of SERCA2. EMBO Rep. 15, 438-445. doi: 10.1002/embr.201337945

Sholtz, K. F., Gorskaya, I. A., and Kotelnikova, A. V. (1983). The stoichiometry of proton translocation through $\mathrm{H}^{+}$-ATPase of rat-liver mitochondria. Eur. J. Biochem. 136, 129-134. doi: 10.1111/j.1432-1033.1983.tb0 7715.x 
Singer, T. P., Castagnoli, N. Jr., Ramsay, R. R., and Trevor, A. J. (1987). Biochemical events in the development of parkinsonism induced by 1-methyl-4-phenyl-1,2,3,6-tetrahydropyridine. J. Neurochem. 49, 1-8. doi: 10.1111/j.1471-4159.1987.tb03384.x

Singh, R., Letai, A., and Sarosiek, K. (2019). Regulation of apoptosis in health and disease: the balancing act of BCL-2 family proteins. Nat. Rev. Mol. Cell. Biol. 20, 175-193. doi: 10.1038/s41580-018-0089-8

Sliter, D. A., Martinez, J., Hao, L., Chen, X., Sun, N., Fischer, T. D., et al. (2018). Parkin and PINK1 mitigate STING-induced inflammation. Nature 561, 258-262. doi: 10.1038/s41586-018-0448-9

Smith, P. M., Fox, J. L., and Winge, D. R. (2012). Biogenesis of the cytochrome $b c_{1}$ complex and role of assembly factors. Biochim. Biophys. Acta 1817, 276-286. doi: 10.1016/j.bbabio.2011.11.009

Souers, A. J., Leverson, J. D., Boghaert, E. R., Ackler, S. L., Catron, N. D., Chen, J., et al. (2013). ABT-199, a potent and selective BCL-2 inhibitor, achieves antitumor activity while sparing platelets. Nat. Med. 19, 202-208. doi: $10.1038 / \mathrm{nm} .3048$

Spikes, T. E., Montgomery, M. G., and Walker, J. E. (2021). Interface mobility between monomers in dimeric bovine ATP synthase participates in the ultrastructure of inner mitochondrial membranes. Proc. Natl. Acad. Sci. U.S.A. 118: e2021012118. doi: 10.1073/pnas.2021012118

Sternlieb, I. (1968). Mitochondrial and fatty changes in hepatocytes of patients with Wilson's disease. Gastroenterology 55, 354-367. doi: 10.1016/S0016-5085(19)34045-4

Stoner, C. D. (1984). Steady-state kinetics of the overall oxidative phosphorylation reaction in heart mitochondria. Determination of the coupling relationships between the respiratory reactions and miscellaneous observations concerning rate-limiting steps. J. Bioenerg. Biomembr. 16, 115-141. doi: 10.1007/BF00743044

Susin, S. A., Zamzami, N., Castedo, M., Hirsch, T., Marchetti, P., Macho, A., et al. (1996). Bcl-2 inhibits the mitochondrial release of an apoptogenic protease. J. Exp. Med. 184, 1331-1341. doi: 10.1084/jem.184.4.1331

Szabó, I., and Zoratti, M. (2014). Mitochondrial channels: ion fluxes and more. Physiol. Rev. 94, 519-608. doi: 10.1152/physrev.00021.2013

Szewczyk, A., Skalska, J., Glab, M., Klawiak, B., Malinska, D., KoszelaPiotrowska, I., et al. (2006). Mitochondrial potassium channels: from pharmacology to function. Biochim. Biophys. Acta 1757, 715-720. doi: 10.1016/j.bbabio.2006.05.002

To, T. L., Cuadros, A. M., Shah, H., Hung, W. H. W., Li, Y., Kim, S. H., et al. (2019). A compendium of genetic modifiers of mitochondrial dysfunction reveals intra-organelle buffering. Cell 179, 1222-1238. doi: 10.1016/j.cell.2019.10.032

Tsai, M. F., Jiang, D., Zhao, L., Clapham, D., and Miller, C. (2014). Functional reconstitution of the mitochondrial $\mathrm{Ca}^{2+} / \mathrm{H}^{+}$antiporter Letm1. J. Gen. Physiol. 143, 67-73. doi: 10.1085/jgp.201311096

Tsukihara, T., Aoyama, H., Yamashita, E., Tomizaki, T., Yamaguchi, H., Shinzawa-Itoh, K., et al. (1996). The whole structure of the 13-subunit oxidized cytochrome c oxidase at 2.8 A. Science 272, 1136-1144. doi: $10.1126 /$ science.272.5265.1136

Twig, G., Elorza, A., Molina, A. J., Mohamed, H., Wikstrom, J. D., Walzer, G., et al. (2008). Fission and selective fusion govern mitochondrial segregation and elimination by autophagy. EMBO J. 27, 433-446. doi: 10.1038/sj.emboj.7601963

Urbani, A., Giorgio, V., Carrer, A., Franchin, C., Arrigoni, G., Jiko, C., et al. (2019). Purified F-ATP synthase forms a $\mathrm{Ca}^{2+}$-dependent high-conductance channel matching the mitochondrial permeability transition pore. Nat. Commun. 10:4341. doi: 10.1038/s41467-019-12331-1

Vaillier, J., Arselin, G., Graves, P. V., Camougrand, N., and Velours, J. (1999). Isolation of supernumerary yeast ATP synthase subunits e and i. Characterization of subunit $\mathrm{i}$ and disruption of its structural gene ATP18. J. Biol. Chem. 274, 543-548. doi: 10.1074/jbc.274.1.543

van Wijngaardeen, G. K., Bethlem, J., Meijer, A. E., Hulsmann, W. C., and Feltkamp, C. A. (1967). Skeletal muscle disease with abnormal mitochondria. Brain 90, 577-592. doi: 10.1093/brain/90.3.577

Wallace, D. C. (2007). Why do we still have a maternally inherited mitochondrial DNA? Insights from evolutionary medicine. Annu. Rev. Biochem. 76, 781-821. doi: 10.1146/annurev.biochem.76.081205.150955

Wallace, D. C., Singh, G., Lott, M. T., Hodge, J. A., Schurr, T. G., Lezza, A. M., et al. (1988). Mitochondrial DNA mutation associated with Leber's hereditary optic neuropathy. Science 242, 1427-1430. doi: 10.1126/science.3201231
Warburg, O. (1956). On the origin of cancer cells. Science 123, 309-314. doi: 10.1126/science.123.3191.309

Warburg, O., Wind, F., and Negelein, E. (1927). The metabolism of tumors in the body. J. Gen. Physiol. 8, 519-530. doi: 10.1085/jgp.8.6.519

Wei, M. C., Lindsten, T., Mootha, V. K., Weiler, S., Gross, A., Ashiya, M., et al. (2000). tBID, a membrane-targeted death ligand, oligomerizes BAK to release cytochrome c. Genes Dev. 14, 2060-2071. doi: 10.1101/gad.14.16.2060

Wei, W., Tuna, S., Keogh, M. J., Smith, K. R., Aitman, T. J., Beales, P. L., et al. (2019). Germline selection shapes human mitochondrial DNA diversity. Science 364:eaau6520. doi: 10.1126/science.aau6520

Weinberg, S. E., Singer, B. D., Steinert, E. M., Martinez, C. A., Mehta, M. M., Martínez-Reyes, I., et al. (2019). Mitochondrial complex III is essential for suppressive function of regulatory T cells. Nature 565, 495-499. doi: 10.1038/s41586-018-0846-z

Westerhoff, H. V., Van der Bend, R. L., van Dam, K., Berden, J., and Peterson, J. (1986). A model system for delocalized chemiosmotic coupling exhibited the features thought diagnostic of localized coupling. Biochem. J. 236, 932-933. doi: 10.1042/bj2360932

Wolf, D. M., Segawa, M., Kondadi, A. K., Anand, R., Bailey, S. T., Reichert, A. S., et al. (2019). Individual cristae within the same mitochondrion display different membrane potentials and are functionally independent. EMBO J. 38:e101056. doi: $10.15252 / \mathrm{embj} .2018101056$

Wollenberger, A., Kleitke, B., and Raabe, G. (1963). Some metabolic characteristics of mitochondria from chronically overloaded, hypertrophied hearts. Exp. Mol. Pathol. 2, 251-260. doi: 10.1016/0014-4800(63)90040-6

Wrogemann, K., and Pena, S. D. (1976). Mitochondrial calcium overload: a general mechanism for cell-necrosis in muscle diseases. Lancet 1, 672-674. doi: 10.1016/S0140-6736(76)92781-1

Xia, D., Yu, C. A., Kim, H., Xia, J. Z., Kachurin, A. M., Zhang, L., et al. (1997). Crystal structure of the cytochrome $b c_{1}$ complex from bovine heart mitochondria. Science 277, 60-66. doi: 10.1126/science.277.5322.60

Yaguzhinsky, L. S., Yurkov, V. I., and Krasinskaya, I. P. (2006). On the localized coupling of respiration and phosphorylation in mitochondria. Biochim. Biophys. Acta 1757, 408-414. doi: 10.1016/j.bbabio.2006.04.001

Yang, J., Liu, X., Bhalla, K., Kim, C. N., Ibrado, A. M., Cai, J., et al. (1997). Prevention of apoptosis by $\mathrm{Bcl}-2$ : release of cytochrome $\mathrm{c}$ from mitochondria blocked. Science 275, 1129-1132. doi: 10.1126/science.275.5303.1129

Yu, C. H., Davidson, S., Harapas, C. R., Hilton, J. B., Mlodzianoski, M. J., Laohamonthonkul, P., et al. (2020). TDP-43 triggers mitochondrial DNA release via mPTP to activate cGAS/STING in ALS. Cell 183, 636-649. doi: 10.1016/j.cell.2020.09.020

Zhang, Q., Raoof, M., Chen, Y., Sumi, Y., Sursal, T., Junger, W., et al. (2010). Circulating mitochondrial DAMPs cause inflammatory responses to injury. Nature 464, 104-107. doi: 10.1038/nature08780

Zhao, Q., Liu, J., Deng, H., Ma, R., Liao, J. Y., Liang, H., et al. (2020). Targeting mitochondria-located circRNA SCAR Alleviates NASH via reducing mROS output. Cell 183, 76-93. doi: 10.1016/j.cell.2020.08.009

Zhong, Z., Liang, S., Sanchez-Lopez, E., He, F., Shalapour, S., Lin, X. J., et al. (2018). New mitochondrial DNA synthesis enables NLRP3 inflammasome activation. Nature 560, 198-203. doi: 10.1038/s41586-018-0372-Z

Zhou, R., Yazdi, A. S., Menu, P., and Tschopp, J. (2011). A role for mitochondria in NLRP3 inflammasome activation. Nature 469, 221-225. doi: 10.1038/nature09663

Zickermann, V., Wirth, C., Nasiri, H., Siegmund, K., Schwalbe, H., Hunte, C., et al. (2015). Structural biology. Mechanistic insight from the crystal structure of mitochondrial complex I. Science 347, 44-49. doi: 10.1126/science.12 59859

Conflict of Interest: The author declares that the research was conducted in the absence of any commercial or financial relationships that could be construed as a potential conflict of interest.

Copyright (c) 2021 Bernardi. This is an open-access article distributed under the terms of the Creative Commons Attribution License (CC BY). The use, distribution or reproduction in other forums is permitted, provided the original author(s) and the copyright owner(s) are credited and that the original publication in this journal is cited, in accordance with accepted academic practice. No use, distribution or reproduction is permitted which does not comply with these terms. 